\title{
DNA fingerprinting of Eucalyptus graniticola: a critically endangered relict species or a rare hybrid?
}

\author{
MAURIZIO ROSSETTO*, FRANKLIN LUCAROTTI, STEPHEN D. HOPPER \& KINGSLEY \\ W. DIXON \\ Kings Park and Botanic Garden, West Perth, Western Australia 6005
}

\begin{abstract}
Eucalyptus graniticola is known from a single plant located on a granite outcrop south-east of Perth in Western Australia. Since its discovery in 1987, it has been uncertain whether this eucalypt is a relict species or a hybrid and, consequently, further study is required in order to devise appropriate conservation strategies. The similarity of features, such as leaf, bud and fruit morphology, to those of $E$. rudis, a common tree found in the vicinity, suggested that $E$. graniticola is a hybrid. This study uses random amplified polymorphic DNA (RAPD) analysis to demonstrate the additive inheritance of DNA markers from $E$. rudis and $E$. drummondii, the putative parent species, in E. graniticola. All the markers detected for E. graniticola using nine primers were shared with either E. rudis ( 40 per cent), E. drummondii (35 per cent) or both parent species (25 per cent). The DNA fingerprinting results, combined with other factors, such as the segregation of cotyledon morphology, demonstrate the hybrid origin of $E$. graniticola. As a result, conservation of this rare eucalypt should rely more on ex situ propagation and storage than on active management.
\end{abstract}

Keywords: conservation genetics, Eucalyptus, hybrid, RAPD, rare flora.

\section{Introduction}

It has been estimated that up to 60000 of the 250000 plant species in the world could be extinct within the next 50 years (Holsinger \& Gottlieb, 1991). Critically endangered species are at the sharp end of today's global extinction crisis. These are species judged most likely to become extinct in the immediate future unless remedial action is taken.

The south-west of Western Australia is a region especially rich in biodiversity and endemism. Of an estimated 8000 species of flowering plants, some 2000 may be of conservation concern (Hopper et al., 1990), with 280 of these being in danger of extinction in the near future (Department of Conservation and Land Management, 1995). Natural (intrinsic) rarity underpins much of this problem. However, the more floristically diverse areas of Western Australia have undergone substantial anthropogenic change, resulting in high levels of endangerment (extrinsic rarity).

\footnotetext{
*Correspondence. E-mail: maurizio@kpbg.wa.gov.au
}

Causes of rarity and critical endangerment are diverse, ranging from direct human destruction of wild ecosystems to processes such as recent evolutionary origin or reproductive failure of relict species under changed environmental circumstances (Fiedler \& Ahouse, 1992; Pate \& Hopper, 1993). A knowledge of such causes is vital for conservation managers interested in preventing extinction.

In this paper, we investigate an extreme case of a taxon, Eucalyptus graniticola Hopper ined., known from a solitary wild individual discovered in 1987 along the Darling Scarp to the south of Perth (Fig. 1). The eucalypt is a lignotuberous mallee $7 \mathrm{~m}$ tall and $8 \mathrm{~m}$ across with some 45 trunks. It occurs in dense heath in a shallow soil pocket on a granite outcrop surrounded by E. marginata forest (Fig. 2a).

Although buds and fruits of $E$. graniticola are reminiscent of those of $E$. rudis, they are smaller (Fig. 2b). Moreover, E. graniticola is a mallee with smooth white bark, whereas $E$. rudis is a tree with a stocking of rough, grey bark (Brooker \& Kleinig, 1990). The apparent rarity of E. graniticola suggests that it is either a relict undescribed species or a rare 
Fig. 1 Geographical distribution of Eucalyptus drummondii and $E$. rudis showing the areas of overlap for the two species and the location of the $E$. graniticola site (data obtained from the WA Herbarium). The demarcation line indicates the south-west botanical province.

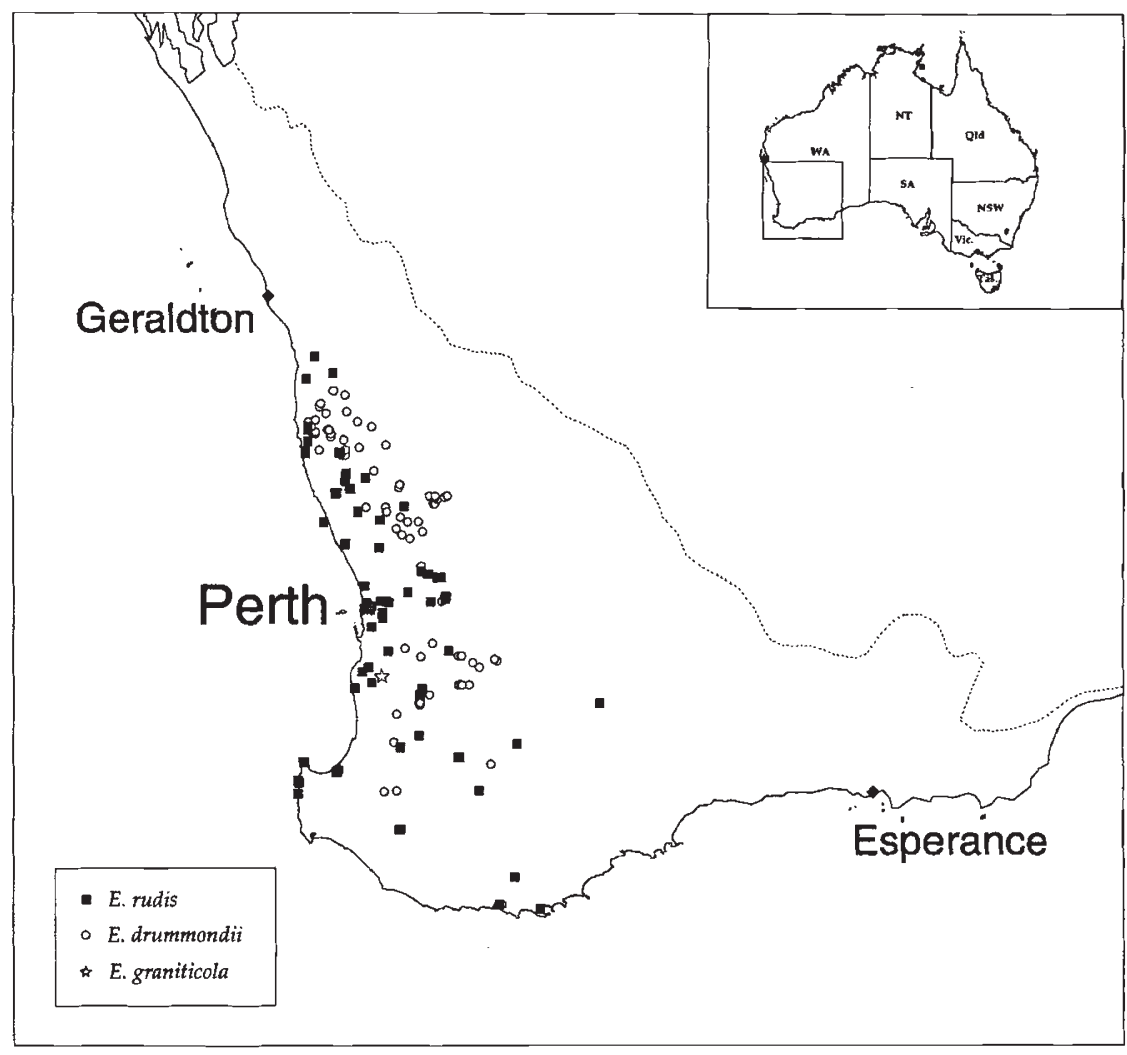

DNA fingerprinting relies on the detection of distinctive, parent-specific DNA markers within the progeny DNA profile. One of the techniques previously used for such a task is random amplified polymorphic DNA (RAPD; Williams et al., 1990), a simple polymerase chain reaction (PCR)-derived technique capable of analysing a large number of loci inherited in a Mendelian fashion. It has been used successfully for detecting the hybrid origin of plant (Crawford et al., 1993; Xu et al., 1993; Rieseberg \& Gerber, 1995) and animal species (Shoemaker et al., 1994; Chu et al., 1995).

This study applies RAPD analysis, progeny trials and fertility tests to resolve the identity of $E$. graniticola. A better understanding of the evolutionary origin of this eucalypt aims to provide basic information crucial for the development of appropriate conservation strategies.

\section{Materials and methods}

\section{Ecological survey}

Extensive searches for E. graniticola were undertaken from 1987 to 1996 on more than 100 granite outcrops throughout the ranges of $E$. rudis and $E$. drummondii. When populations were encountered, a 
full inventory of associated species was made and the microhabitat occupied was recorded.

\section{Plant material}

Voucher material of $E$. graniticola has been deposited at the Western Australian Herbarium.

Leaf material for DNA extraction was collected from $E$. graniticola and the closest known populations of the putative parents.

In order to test whether the only known $E$. graniticola mallee was a single plant, samples were collected from two opposite ends of the clump (g1 and g2).

Samples were collected from six distinct E. drummondii plants (d1-d6) at two sites on Mount Wells
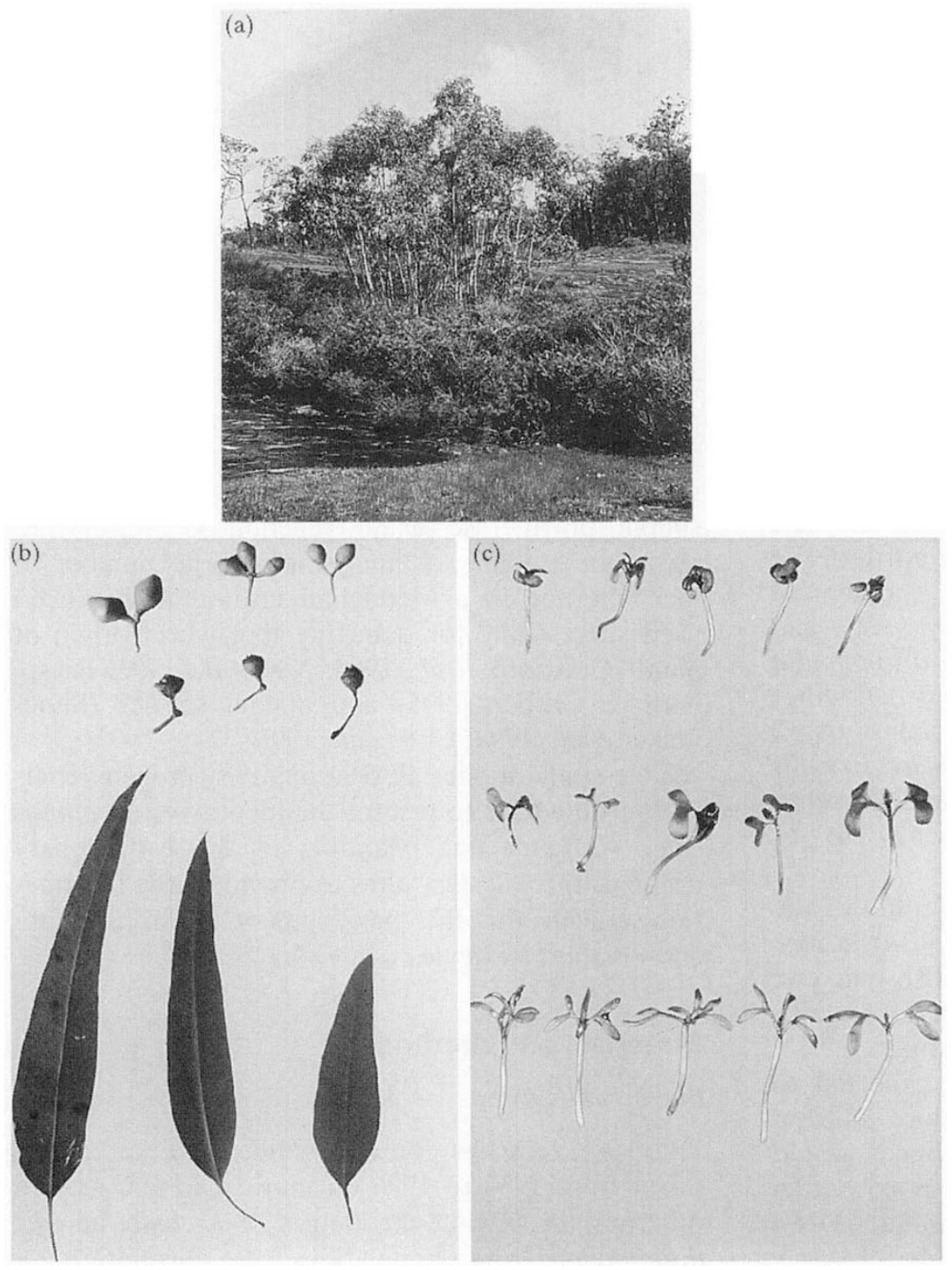

Fig. 2 (a) The only known Eucalyptus graniticola plant in the wild. (b) Comparison of flower bud, fruit and leaf morphology for E. drummondii (right), E. graniticola (centre) and $E$. rudis (left). (c) Seedlings showing different cotyledon morphology for E. rudis (top), E. graniticola (centre) and $E$. drummondii (bottom). 
Seeds were counted and subsequently germinated in the dark on moist filter paper. After germination, they were transferred to the light and eventually transferred to soil in a glasshouse. Number of seeds, germination success and cotyledon morphology were recorded.

Fresh anthers were squashed in a drop of acetocarmine on a microscope slide, and a minimum of 200 grains were scanned for stainability and shape as indicators of viability.

\section{Polymerase chain reaction}

DNA was extracted using a sodium dodecyl sulphate (SDS) protocol described by Rossetto et al. (1995). PCR was performed in a $12.5 \mu \mathrm{L}$ total volume containing $50 \mathrm{~mm} \mathrm{KCl}, 10 \mathrm{~mm}$ Tris- $\mathrm{HCl}(\mathrm{pH} 9.0), 0.1$ per cent Triton X-100, $2.0 \mathrm{~mm} \mathrm{MgCl}_{2}, 0.2 \mathrm{~mm}$ of each dNTP, 0.5 units of Tth DNA polymerase (Biotech International), $50 \mathrm{ng}$ of primer, $10 \mathrm{ng}$ of DNA and DNA-free water. Each reaction mix was overlaid with $20 \mu \mathrm{L}$ of PCR-grade paraffin oil. In order to test reproducibility, duplicate reactions were run and, if the banding patterns obtained were not reproducible, the primers were not used for the full course of the experiment. After selection, six 9-bp primers and three 10-bp primers were used (Table 1). PCR reactions were performed on a Hybaid OmniGene thermocycler programmed for an initial melting step at $94^{\circ} \mathrm{C}$ for $5 \mathrm{~min}$, followed by 35 cycles each at $94^{\circ} \mathrm{C}$ for $15 \mathrm{~s}, 34^{\circ} \mathrm{C}$ for $45 \mathrm{~s}, 72^{\circ} \mathrm{C}$ for $1 \mathrm{~min}$. A final extension step at $72^{\circ} \mathrm{C}$ for $10 \mathrm{~min}$ was performed after the 35 cycles. A negative control reaction, in which DNA was omitted, was included with every PCR run in order to verify the absence of contamination.

\section{Data analysis}

Amplification products were resolved electrophoretically on 2 per cent agarose gels run at $60 \mathrm{~V}$ in TBE and visualized by staining with ethidium bromide. Lambda DNA cut with EcoRI/HindIII was used as a size marker. The gel images were digitized directly from the UV transluminator through a Sony SSC-M370 SE high resolution, black and white video camera. The images were then analysed using CREAM for Windows (Kementec) image analysis software.

The presence/absence data were used to obtain an estimate of similarity using Nei \& Li's (1979) similarity index, calculated as $F=2 m_{x y} /\left(m_{x}+m_{y}\right)$, where $m_{x y}$ is the number of shared markers between two samples and $m_{x}$ and $m_{y}$ the number of markers for each sample. Group estimates were calculated by averaging interindividual similarities obtained for each group considered.

UPGMA analysis was carried out on the matrix of genetic similarity calculated using Nei \& Li's (1979) index, and a dendrogram representing similarities between the 17 samples representing three taxa was obtained from it.

\section{Hybrid band homology assessment}

Assessment to test homology of parental/hybrid bands was performed using the two $E$. graniticola samples, four $E$. drummondii samples and four $E$.

Table 1 Summary of data obtained by RAPD analysis for six 9-bp-long primers and three 10-bp-long primers for the three eucalypts

\begin{tabular}{lcccc}
\hline $\begin{array}{l}\text { Primer sequence } \\
5^{\prime} \text { to 3' }\end{array}$ & $\begin{array}{c}\text { No. of bands } \\
\text { for E. graniticola }\end{array}$ & $\begin{array}{c}\text { No. of bands for } \\
\text { E. drummondii }\end{array}$ & $\begin{array}{c}\text { No. of bands for } \\
\text { E. rudis }\end{array}$ & $\begin{array}{c}\text { Approx. band size } \\
\text { range (bp) }\end{array}$ \\
\hline CCCACCAAC & 5 & 7 & 5 & $500-1250$ \\
CCCTCCTTC & 5 & 7 & 4 & $530-1080$ \\
GGGTTGTGG & 5 & 8 & 7 & $270-990$ \\
GGGAGGAAG & 4 & 6 & 6 & $270-1150$ \\
GGGTGGTTG & 8 & 8 & 8 & $370-940$ \\
GGGTGTTGG & 5 & 7 & 6 & $260-1110$ \\
TGAGCGGACA & 3 & 4 & 5 & $640-1500$ \\
CAGGCGCACA & 4 & 7 & 3 & $680-1510$ \\
CGGTGGCGAA & 4 & 57 & 50 & $600-1820$ \\
Total & 43 & 7 & 6 & $260-1820$ \\
\hline
\end{tabular}

The table shows primer sequence, number of markers obtained with each primer for each taxon and the approximate size range of the markers detected. 
rudis samples. The 640-bp fragment detected for $E$. graniticola and $E$. rudis and the 1210-bp fragment detected for E. graniticola and E. drummondii using primer TGAGCGGACA were tested using Southern hybridization. Amplification products were transferred to an Amersham Hybond $\mathrm{N}^{+}$nylon membrane and hybridized according to the manufacturer's instructions. Putative homologous fragments were isolated from an agarose gel with a Qia ex II (Qiagen) gel purification procedure and labelled with $\left[\hat{\gamma}^{32} \mathrm{P}\right] \mathrm{dATP}$. Hybridization protocols were similar to those of Byrne et al. (1993), except hybridizations and stringent washes were carried out at $50^{\circ} \mathrm{C}$.

\section{Results}

\section{Ecological study}

Eucalyptus graniticola was only found at its type location, which is seasonally wet as a result of catchment from the surrounding sheet rock. It occurs in a 20-m-diameter soil pocket, with species favouring damp soils with high runoff, such as Calothamnus quadrifidus (Myrtaceae), Acacia oncinophylla (Mimosaceae), Grevillea bipinnatifida (Proteaceae) and Lepidosperma spp. (Cyperaceae).

Eucalyptus rudis and E. drummondii were rarely found on granite outcrops, at two and three sites, respectively. Eucalyptus rudis is a riparian or wet-site tree growing to $15 \mathrm{~m}$, usually in waterlogged soils. When on granite, E. rudis is more abundant along adjacent creeklines, with just a few plants colonizing soil pockets upslope, growing with species of Calothamnus, Lepidosperma and Hypocalymma (Myrtaceae).

Eucalyptus drummondii is a small to medium tree growing to $5 \mathrm{~m}$ and usually occurs in drier, welldrained sites on the slopes and crests of hills and lateritic breakaways. On granite, it grows in shallow soils on dry north-facing slopes, with species such as Gastrolobium spinosum (Fabaceae), Xanthorrhoea preissii (Xanthorrhoeaceae) and Daviesia horrida (Fabaceae). These sites are usually upslope from large areas of sheet rock and do not enjoy significant runoff or waterlogging. Their dry soils are characterized by the absence of species of Lepidosperma and Calothamnus.

\section{Morphological study}

Eucalyptus graniticola is an erect-stemmed mallee growing to $4 \mathrm{~m}$ high with smooth, creamy and powdery bark, dull leaves, $11 \mathrm{~cm}$ long by $2.5 \mathrm{~cm}$ wide, globular buds up to $9 \mathrm{~mm}$ long by $6 \mathrm{~mm}$ in diameter with a conical operculum, and a small subcampanulate fruit $6 \mathrm{~mm}$ long by $7 \mathrm{~mm}$ in diameter.

The cotyledon morphology of germinated E. graniticola seeds showed clear segregation between that of $E$. rudis (flat-kidney shaped) and that of $E$. drummondii (Y-shaped) (Fig. 2c).

Similarly, leaf length, bud and fruit shape of $E$. graniticola were intermediate between those of the putative parent species (Fig. 2b).

\section{Seed and pollen viability}

The number of viable seeds was lower in E. graniticola ( 0.2 seeds per fruit) than in E. drummondii (1.1 seeds per fruit) and $E$. rudis ( 0.8 seeds per fruit).

Similarly, pollen fertility was estimated at 23 per cent for E. graniticola compared with 82 per cent or more for both $E$. drummondii and $E$. rudis.

\section{Marker description and distribution}

Table 1 summarizes the banding pattern obtained with the nine primers for the three eucalypts studied. A total of 96 scorable markers were detected for all the samples tested with nine primers. The 9-bp-long primers consistently produced a greater number of markers (average of 6.2 per species) than the 10-bp-long primers (average of 4.3 per species). Eucalyptus drummondii produced the greatest number of markers (average of 6.3 per primer), followed by E. rudis (average of 5.6 per primer) and E. graniticola (average of 4.8 per primer).

Figure $3 \mathrm{a}$ illustrates the type of banding pattern obtained for the three taxa with one of the primers used (TGAGCGGACA). The gel shows that all the markers visualized for E. graniticola with the primer are shared either with $E$. rudis or with $E$. drummondii. Figure 3 also shows a clear negative control, which was the case for all the reactions used in this study.

Table 2 shows that all the markers identified for E. graniticola were found in either E. rudis ( 40 per cent), E. drummondii (35 per cent) or both (25 per cent). In other words, E. graniticola has no exclusive and specific markers. Eucalyptus drummondii and $E$. rudis share 25 per cent and 28 per cent of their markers with each other and possess 49 per cent and 38 per cent exclusive markers, respectively.

Southern hybridization showed homology for the fragments selected to represent parental markers within the fingerprint of the putative hybrid (Fig. 3b). 


\section{Estimate of similarity}

Table 3 shows the estimate of similarity within each taxon and the comparisons of similarity between taxa. The two samples obtained from opposite ends of the E. graniticola clump showed identical fingerprints. Within-species similarity ranged from 78 per cent to 88 per cent for the other eucalypts. If the $E$. drummondii sample and the small-fruited $E$. drummondii sample are grouped together, the similarity within these 10 plants is 79 per cent.

Table 3 shows high within-species similarity, even though it must be taken into account that the individuals tested represent only a small sample of the species. However, between-species similarity is low between the putative parents ( 26 per cent). This is not the case for $E$. graniticola, which shows high similarity to $E$. rudis (65 per cent) and to $E$. drummondii (52 per cent), as well as to the small-fruited $E$. drummondii (57 per cent). The small-fruited $E$. drummondii sample is highly similar to $E$. drummondii (75 per cent), but not to E. rudis (26 per cent).

The dendrogram in Fig. 4 illustrates the similarities between the 17 individuals tested, based on similarity results obtained by RAPD analysis. The major taxa are clustered, whereas $E$. rudis and $E$. drummondii are distant (with the small-fruited $E$. drummondii within the $E$. drummondii clump), whereas $E$. graniticola is intermediate between the two potential parent species.

\section{Discussion}

\section{Evidence for hybrid derivation of E. graniticola}

RAPD analysis has clearly demonstrated the additive inheritance of DNA markers in $E$. graniticola arising from both $E$. rudis and $E$. drummondii. On this evidence, the identity of $E$. graniticola as a rare hybrid of these parental taxa is strongly supported.

The theory behind the detection of parent speciesspecific markers in a hybrid by RAPD analysis is that first-generation hybrids contain a set of chromosomes from each of the parent species and will thus share all their markers with one or the other parent species. As no specific markers to E. graniticola were detected, this implies that the plant is a first-generation hybrid. If no segregation or backcrossing with
Fig. 3 (a) Agarose gel showing the results obtained using primer TGAGCGGACA. Lane 1 is a size marker, lanes 2-7 are Eucalyptus rudis samples, lanes 8 and 9 are $E$. graniticola samples, lanes $10-18$ are E. drummondii samples. The $1210-\mathrm{bp}$ fragment and the 640-bp fragment, from the same primer and used for hybridization, are also indicated. (b) Results from the hybridization of the two fragments indicated in Fig. 3a. Lanes 1-4, E. rudis; lanes 5-6 and 7-8, E. graniticola; lanes 9-12, E. drummondii.
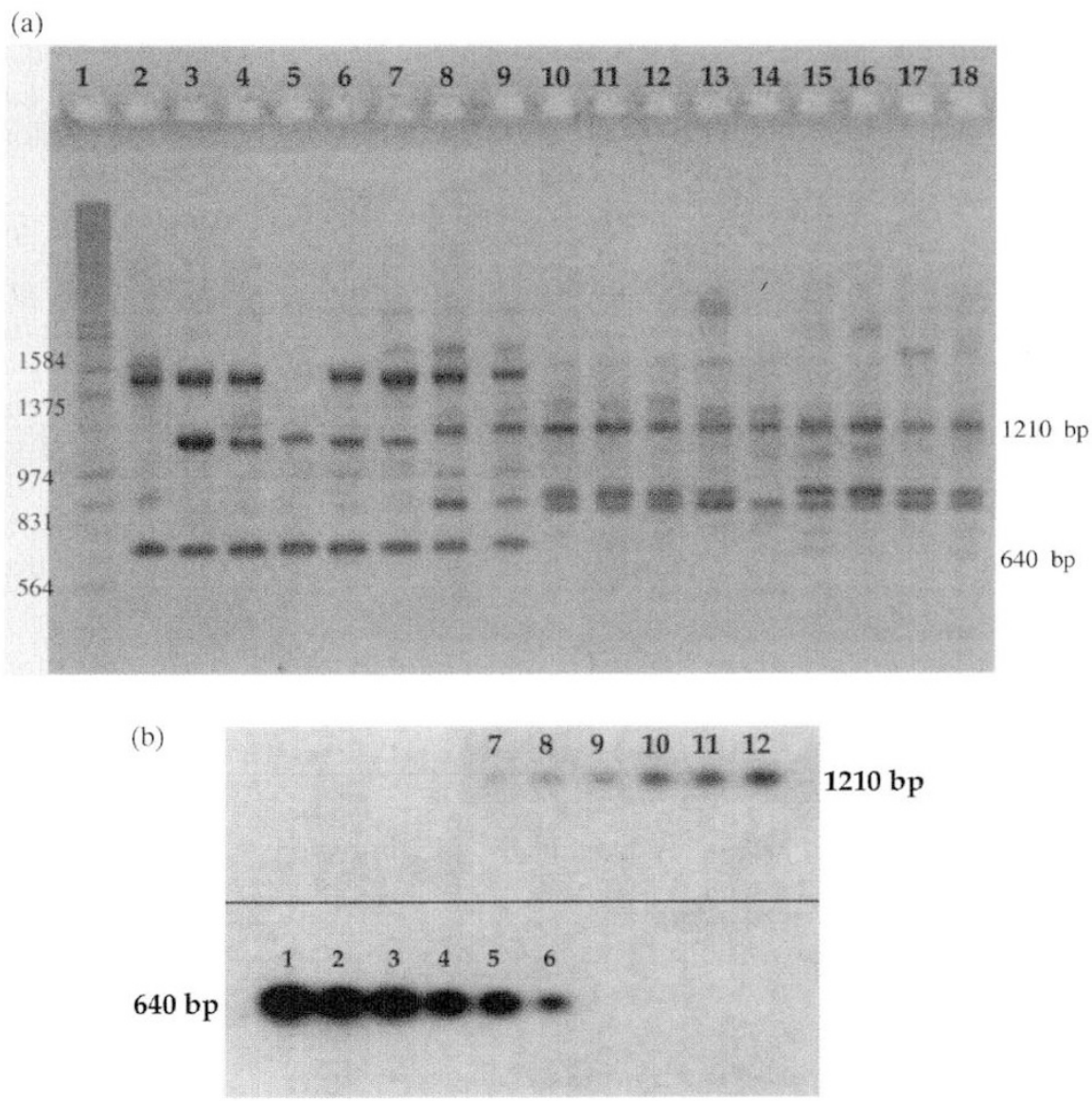
Table 2 Percentage of the 43 markers detected for Eucalyptus graniticola with nine primers, which were exclusive to E. graniticola, shared with E. rudis, shared with E. drummondii and shared with both species

\begin{tabular}{lc}
\hline Markers recorded for E. graniticola & Percentage $(n)$ \\
\hline Exclusive to E. graniticola & $0(0)$ \\
Shared with E. rudis & $40(17)$ \\
Shared with E. drummondii & $35(15)$ \\
Shared with E. rudis and E. drummondii & $25(11)$ \\
\hline
\end{tabular}

the parent species has occurred, no new markers are expected, unless they are derived from mutations (but the probability of detecting these is low). The results from RAPD analysis (Table 2) show that $E$. graniticola does not possess any exclusive and distinctive markers, because all its markers were detected in either or both parent species.

RAPD analysis has been challenged as a reliable technique owing to the production of nonparental markers in progeny fingerprints (Riedy et al., 1992). However, this was not the case in this study, and it seems to be a relatively rare event. For instance, Scott et al. (1992) only found 0.002 per cent (from 824 reactions) nonparental markers in Fragaria vesca and 0.012 per cent (from 1450 reactions) in Nicrophorus tomentosus. Similarly, the lack of homology in co-migrating fragments has sometimes been raised as a potential problem. For example, in an extreme case, Rieseberg (1996) detected up to 20 per cent nonhomologous co-migrating fragments in three species of Helianthus. However, in this study, the lack of exclusive E. graniticola markers and the verification of homology for the selected co-migrating fragments (Fig. 3b) confirm the results obtained by RAPD analysis.

Corroboration of this result is provided by the similarity analysis. Similarity between the two different species ( 26 per cent) is much lower than that between the hybrid and its parent species (65 per cent with $E$. rudis and 52 per cent with $E$. drummondii).

The segregation of cotyledon characters in the progeny of E. graniticola (Fig. 2c), intermediate leaf, bud and fruit morphology (Fig. 2b), low seed and pollen viability and occupancy of an intermediate habitat strongly support the proposed hybrid origin of E. graniticola (Hopper, 1995). However, it is important to realize that reliable recognition of hybrids cannot always depend on morphological similarities alone as these can have other origins (Hopper, 1995).

Eucalyptus is the genus with the highest number of recorded interspecific hybrids in Western Australia (Hopper, 1995). Yet the formation of a hybrid between $E$. rudis and $E$. drummondii is a surprising event, as these species are not closely related.

RAPD analysis was also able to demonstrate for E. graniticola that it is likely that all 45 stems arising from ground level were genetically identical and likely to have arisen from a single mallee rootstock. The similarity data also indicate that the smallfruited eucalypt found in the vicinity of the rare hybrid is E. drummondii and not another hybrid or a new species. In order to determine whether the small-fruited eucalypt is simply a form or a distinct subspecies, a study including the entire E. drummondii distribution should be carried out.

\section{Origin of E. graniticola}

Eucalyptus graniticola is a hybrid that originated when $E$. rudis and $E$. drummondii occurred at that same site.

The two parent species are still found in the near vicinity and granite outcrops represent a rare juxtaposition of their habitats. Eucalyptus rudis and E. drummondii are not commonly found in the same area and this, plus the distant taxonomic relation-

Table 3 Genetic similarity within and between Eucalyptus taxa, calculated as for Nei \& Li (1979) $F=2 m_{x y} /\left(m_{x}+m_{y}\right)$, using the presence/absence data obtained from RAPD analysis

\begin{tabular}{lcccc}
\hline & $\begin{array}{c}\text { E. rudis } \\
(n=5)\end{array}$ & $\begin{array}{c}\text { E. graniticola } \\
(n=2)\end{array}$ & $\begin{array}{c}\text { E. drummondii } \\
(n=6)\end{array}$ & $\begin{array}{c}\text { Small-fruited } \\
(n=4)\end{array}$ \\
\hline E. rudis & 0.78 & & & \\
E. graniticola & 0.65 & 1.00 & & \\
E. drummondii & 0.26 & 0.52 & 0.82 & 0.88 \\
Small-fruited E.d. & 0.26 & 0.57 & 0.75 & 0.80 dii \\
\hline
\end{tabular}




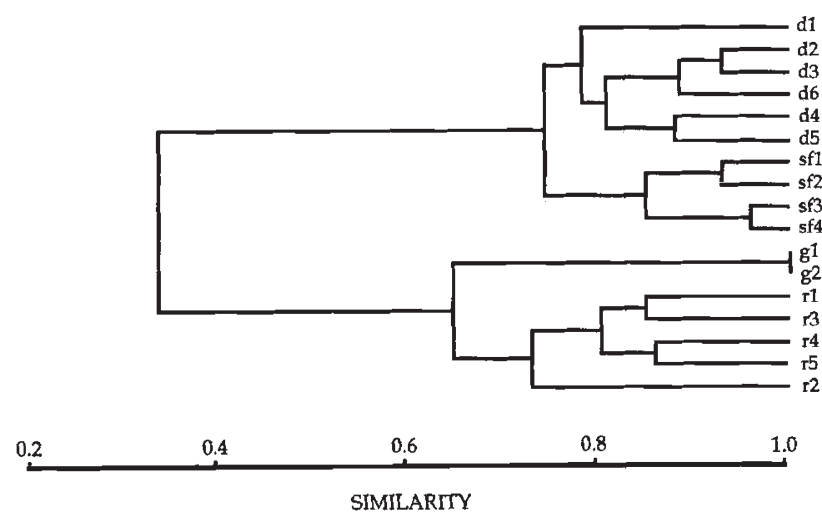

Fig. 4 Dendrogram showing the relationships between the taxa tested. d1-d6, Eucalyptus drummondii samples; sf1-sf4, small-fruited E. drummondii samples; g1 and g2, E. graniticola samples; r1-r5, E. rudis samples.

ship between them, may explain why this hybrid is rare.

The distribution of $E$. rudis and $E$. drummondii could have been reduced by Quaternary climatic fluctuations and/or by recent disturbances, such as changes in fire frequency and logging-related pressures. Thus, E. graniticola appears to be a relict of past reproductive interaction, signalling populations of the parent species now extinct. If, as the molecular data seem to indicate, E. graniticola is a firstgeneration hybrid, this reproductive interaction could be more recent than previously anticipated.

Similarly, the small-fruited $E$. drummondii could potentially be a remnant of a once more widespread subspecies.

\section{Conservation strategy}

Eucalyptus graniticola is a natural hybrid representing a unique combination of genetic material that may justify its conservation.

Simply determining the parentage of rare hybrids is not sufficient; the conservation consequences of such findings need to be understood. There are traditional prejudices and reservations against the conservation of natural hybrids (e.g. O'Brien \& Mayr, 1991), and conservation biologists and managers may need further information before deciding on conservation actions. For instance, when determining the parentage of a rare hybrid mahogany, Rieseberg \& Gerber (1995) were concerned that outbreeding depression could occur in the remaining Cercocarpus traskiae plants (one of the parent species), resulting in reduced seed-set and eventually driving the species to extinction. In addition, the risk existed of genetic assimilation of the rare species by hybridization, especially in such a restricted and disturbed habitat (Catalina island). As a result, although recognizing the conservation value of the hybrid, the authors recommended its transplantation to a location where no parent species are found.

Eucalyptus graniticola is restricted to one potentially aged individual and is not ecologically aggressive, as the distances involved mitigate against backcrossing to the parental taxa and seed production is low. Furthermore, both parent species are common and widespread and, therefore, not in danger of genetic swamping. Being the only known representative of a natural hybrid between $E$. rudis and $E$. drummondii, E. graniticola represents a valuable genetic package of great scientific and some horticultural interest and is, therefore, worthy of conservation attention. Furthermore, being a mixture of two such distant taxa might have produced some adaptive advantages for such a large mallee to survive in the difficult granite rock environment where dry/wet extremes can be expected.

Finding the hybrid origin of E. graniticola helps in defining the conservation strategy to be adopted for this taxon. If it were a relict species, decreasing in number because of anthropomorphic pressure, reinforcement of the existing population (i.e. plant) would have been seen as one of the main options for the species recovery. However, being a long-lived resprouting hybrid, adequately protected and under no immediate danger, reinforcement is not recommended for this eucalypt, and the main conservation objective with this taxon is ex situ conservation. A programme to establish the species in tissue culture and cryopreservation has been successfully undertaken at Kings Park and Botanic Garden (Rossetto et al., 1993; D. H. Touchell, unpublished observations) so that the species is conserved ex situ.

\section{Acknowledgements}

The authors would like to acknowledge the assistance of ALCOA Australia, J. Koch, G. Jezierski, M. Waycott and the Western Australian Herbarium. This project was partly funded by ALCOA Australia.

\section{References}

BROOKER, M. I. H. AND KleINIG, D. A. 1990. A Field Guide to Eucalypts, vol. 2. Inkata Press, Melbourne, Australia.

BYRNE, M., MORAN, G. F. AND TIBBITS, w. N. 1993. Restriction map and maternal inheritance of chloroplast DNA in Eucalyptus nitens. J. Hered., 84, 218-220. 
CHU, J., POWERS, E. AND HOWARD, D. J. 1995. Gene exchange in a ground cricket hybrid zone. J. Hered., 86, 17-21.

CRAWFORD, D. J., BRAUNER, S., COSNER, M. B. AND STUESSY, T. F. 1993. Use of RAPD markers to document the origin of the intergeneric hybrid $\times$ Margyracaena skottsbergii (Rosaceae) on the Juan Fernandez Islands. Am. J. Bot., 80, 89-92.

DEPARTMENT OF CONSERVATION AND LAND MANAGEMENT. 1995. Declared Rare and Priority Flora List. Department of Conservation and Land Management, Western Australia.

FIEDLER, P. L. AND AHOUSE, S. J. 1992. Hierarchies of cause: towards an understanding of rarity in vascular plant species. In: Fiedler, P. L. and Jain, S. K. (eds) Conservation Biology: the Theory and Practice of Nature Conservation, Preservation and Management, pp. 23-47. Chapman \& Hall, New York.

Holsinger, K. E. AND GOTTlieb, L. D. 1991. Conservation of rare and endangered plants: principles and prospects. In: Falk, D. A. and Holsinger, K. E. (eds) Genetics and Conservation of Rare Plants, pp. 195-208. Oxford University Press, New York.

HOPPER, S. D. 1995. Evolutionary networks: natural hybridization and its conservation significance. In: Saunders, D. A., Craig, J. L. and Mattiske, E. M. (eds) Nature Conservation 4: the Role of Networks, pp. 51-66. Surrey Beatty \& Sons, Chipping Norton, NSW.

HOPPER, S. D., VAN LEEUWEN, S., BROWN, A. AND PATRICK, s. 1990. Western Australia's Endangered Flora. Department of Conservation and Land Management, Western Australia.

NEI, M. AND LI, W. H. 1979. Mathematical model for studying genetical variation in terms of restriction endonucleases. Proc. Natl. Acad. Sci. U.S.A., 74, 5267-5273.

O'BRIEN, S. J. AND MAYR, E. 1991. Bureaucratic mischief: recognizing 'endangered' species and subspecies. Science, 251, 1187-1188.
PATE, J. S. AND HOPPER, S. D. 1993. Rare and common plants in ecosystems, with special reference to the south-west Australian flora. In: Schulze, E. D. and Mooney, H. A. (eds) Biodiversity and Ecosystem Function, pp. 293-325. Springer, Berlin.

RIEDY, M. F., HAMILTON, W. J., III, AND AQUADRO, C. F. 1992. Excess of non-parental bands in offspring from known primate pedigrees assayed using RAPD PCR. Nucl. Acids Res., 20, 918.

RIESEBERG, L. H. 1996. Homology among RAPD fragments in interspecific comparisons. Mol. Ecol., 5, 99-105.

RIESEBERG, L. H. AND GERBER, D. 1995. Hybridization in the Catalina Island mountain mahogany (Cercocarpus traskiae): RAPD evidence. Conserv. Biol., 9, 199-203.

RUSSETTO, M., DIXON, K. W. AND BUNN, E. 1993. Integrated Conservation of Rare Flora. Minerals and Energy Research Institute of Western Australia, Report no. 112.

ROSSETTO, M., WEAVER, P. K. AND DIXON, K. W. 1995. Use of RAPD analysis in devising conservation strategies for the rare and endangered Grevillea scapigera (Proteaceae). Mol. Ecol., 4, 321-329.

SCOTT, M. P., HAYMES, K. M. AND WILliAmS, S. M. 1992. Parentage analysis using RAPD PCR. Nucl. Acids Res., 20, 5493.

ShOEMAKER, D. D., ROSS, K. G. AND ARNOLD, M. L. 1994. Development of RAPD markers in two introduced fire ants, Solenopsis invicta and S. richteri, and their application to the study of a hybrid zone. Mol. Ecol., 3, $531-539$.

WILLIAMS, J. G. K., KUBELIK, A. R., LIVAK, K. J., RAFALSKY, J. A. AND TINGEY, s. V. 1990. DNA polymorphism amplified by arbitrary primers are useful as genetic markers. Nucl. Acids Res., 18, 6531-6535.

XU, Y., ClARK, M. S. AND PEHU, E. 1993. Use of RAPD markers to screen somatic hybrids between Solanum tuberosum and S. brevidens. Pl. Cell Rep., 12, 107-109. 